\title{
The Effectiveness of Deep Oscillation Therapy on Reducing Swelling and Pain in Athletes With Acute Lateral Ankle Sprains
}

\author{
Matt Hausmann, Jacob Ober, and Adam S. Lepley
}

\begin{abstract}
Clinical Scenario: Ankle sprains are the most prevalent athletic-related musculoskeletal injury treated by athletic trainers, often affecting activities of daily living and delaying return to play. Most of these cases present with pain and swelling in the ankle, resulting in decreased range of motion and strength deficits. Due to these impairments, proper treatment is necessary to avoid additional loss of play and prevent future injuries. Recently, there has been an increased use of deep oscillation therapy by clinicians to manage pain and swelling following a variety of injuries, including ankle sprains. However, very little evidence has been produced regarding the clinical effectiveness of deep oscillation therapy, limiting its application in therapeutic rehabilitation of acute lateral ankle sprains. Clinical Question: Is deep oscillation therapy effective in reducing pain and swelling in patients with acute lateral ankle sprains compared with the current standard of care protection, rest, ice, compression, and elevation? Summary of Key Findings: The literature was searched for studies of level 2 evidence or higher that investigated deep oscillation therapy on pain and inflammation in patients with lateral ankle sprains. Three randomized control trials were located and appraised. One of the 3 studies demonstrate a reduction in pain following 6 weeks of deep oscillation therapy compared with the standard of care or placebo interventions. The 2 other studies, 1 utilizing a 5-day treatment and the other a 1 time immediate application, found no differences in deep oscillation therapy compared with the standard of care. Clinical Bottom Line: There is inconclusive evidence to support the therapeutic use of deep oscillation therapy in reducing pain and swelling in patients with acute lateral ankle sprains above and beyond the current standard of care. In addition, the method of treatment application and parameters used may influence the effectiveness of deep oscillation therapy. Strength of Recommendation: Level B.
\end{abstract}

Keywords: HIVAMAT, effusion, visual analog scale

\section{Clinical Scenario}

Ankle sprains are the most prevalent athletic-related musculoskeletal injury treated by athletic trainers, often affecting activities of daily living and delaying return to play. ${ }^{1}$ Most of these cases present with pain and swelling in the ankle, resulting in decreased range of motion and strength deficits. ${ }^{1}$ Due to these impairments, proper treatment is necessary to avoid additional loss of play and prevent future injuries. Recently, there has been an increased use of deep oscillation therapy by clinicians to manage pain and swelling following a variety of injuries, including ankle sprains. However, very little evidence has been produced regarding the clinical effectiveness of deep oscillation therapy, limiting its application in therapeutic rehabilitation of acute lateral ankle sprains.

\section{Clinical Question}

Is deep oscillation therapy effective in reducing pain and swelling in patients with acute lateral ankle sprains compared with the current standard of care protection, rest, ice, compression, and elevation?

\section{Summary of Key Findings}

- The literature was searched for studies of level 2 evidence or higher that investigated deep oscillation therapy on pain and inflammation in patients with lateral ankle sprains.

The authors are with the Department of Kinesiology, University of Connecticut, Storrs, CT. Dr. Lepley is also with the Department of Orthopaedic Surgery, University of Connecticut, Farmington, CT. Lepley (Adam.Lepley@uconn.edu) is corresponding author.
- Three randomized control trials were located and appraised.

- One of the 3 studies demonstrate a reduction in pain following 6 weeks of deep oscillation therapy compared with the standard of care or placebo interventions.

- The 2 other studies, 1 utilizing a 5-day treatment and the other a 1-time immediate application, found no differences in deep oscillation therapy compared with the standard of care.

\section{Clinical Bottom Line}

There is inconclusive evidence to support the therapeutic use of deep oscillation therapy in reducing pain and swelling in patients with acute lateral ankle sprains above and beyond the current standard of care. In addition, method of treatment application and parameters used may influence the effectiveness of deep oscillation therapy.

\section{Strength of Recommendation}

Based on the Oxford Centre for Evidence-Based Medicine scale, level B evidence exists. Although each article examined was a randomized control trial, low PEDro scores and methodological limitations (ie, lack of parameter reporting, variety in length of interventions used, inconclusive results, etc) hinder the immediate application of deep oscillation therapy in the clinical setting for reducing pain and swelling in patients with acute lateral ankle sprains. Further research is needed and is likely to have an important impact on the recommendation on deep oscillation therapy use. 


\section{Search Strategy}

\section{Terms Used to Guide Search Strategy}

- Patient/client group: ankle sprains AND athlete

- Intervention (or Assessment): deep oscillation therapy

- Comparison: cryotherapy AND compression

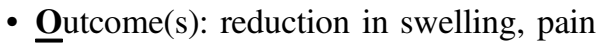

\section{Sources of Evidence Searched}

- The Cochrane Library

- PubMed

- PEDro Database

- MEDLINE

- CINAHL

- SPORTDiscus

\section{Inclusion and Exclusion Criteria}

\section{Inclusion}

- Limited to English language

- Limited to humans

- Limited to the last 10 years (2008-2018)

- Level 2 evidence or higher

- Studies investigating common treatments of acute lateral ankle sprains

\section{Exclusion}

- Studies investigating multiple lower-extremity pathologies

- Studies investigating adolescents

\section{Results of Search}

Three relevant studies ${ }^{2-4}$ were located and categorized as shown in Table 1 (based on levels of evidence, Centre for Evidence Based Medicine). ${ }^{5}$

\section{Best Evidence}

The following studies were identified as the "best" evidence and selected for inclusion in the critically appraised topic (CAT) (Table 2). These studies were selected because they had a level of evidence grade of at least 2 , randomly compared deep oscillation therapy with standard of care treatment of ankle sprains and explained the effect of deep oscillation on pain and swelling.

\section{Table 1 Summary of Study Designs of Articles} Retrieved

\begin{tabular}{lccl}
\hline $\begin{array}{l}\text { Level of } \\
\text { evidence }\end{array}$ & $\begin{array}{c}\text { Study design/ } \\
\text { methodology }\end{array}$ & $\begin{array}{c}\text { Number } \\
\text { located }\end{array}$ & \multicolumn{1}{c}{ Author } \\
\hline $\mathrm{Ib}$ & Randomized control trial & 3 & $\begin{array}{l}\text { Winkelmann et } \mathrm{al}^{2} \\
\text { Aliyev }^{3} \\
\text { Friesen }^{4}\end{array}$ \\
\hline
\end{tabular}

\section{Implications for Practice, Education, and Future Research}

Deep oscillation therapy is a modality that uses repetitive electrostatic oscillations that is theorized to improve relief from pain and swelling by mobilizing lymph fluid and swelling back into body circulation. ${ }^{6}$ The low-frequency electrostatic field is thought to produce a pulsating effect in underlying tissues, directly enhancing the movement of swelling via the lymphatic system and bringing more blood to the affected area. ${ }^{6,7}$ However, the results of the current CAT do not support the use of deep oscillation therapy for the purpose of reducing pain and swelling following an acute lateral ankle sprain.

Each of the 3 reviewed articles only included patients with low-grade acute lateral ankle sprain, within 48 to 72 hours ${ }^{2,3}$ and up to 1 week $^{3}$ following injury, meaning these results are generalizable to a specific patient population. Of the 3 studies reviewed in this CAT, only 1 study ${ }^{3}$ described statistically significant reduction in swelling and pain after acute ankle sprains in the deep oscillation therapy condition compared with the standard of care. The study above states that on the visual analog scale (0-10), patients in the treatment group improved from 9 (2) to 2 (2) compared with the control group whose pain decreased from 8 (2) to 5 (3). This same study found that after a 6 -week treatment protocol, the treatment group had $0.2 \mathrm{~cm}$ of swelling remaining compared with $0.8 \mathrm{~cm}$ from the control group, as measured at the smallest circumference of the lower leg, ankle, and instep of the navicular bone. ${ }^{3}$ According to this study, deep oscillation therapy is effective at reducing pain and swelling, while promoting joint stability.

Despite the significant results from the study above, 2 other studies were statistically inconclusive on whether deep oscillation therapy has an effect on pain and swelling. ${ }^{2,4}$ Winkelmann et $\mathrm{al}^{2}$ determined that immediately following 1 treatment of deep oscillation therapy, there was an immediate reduction in pain and swelling, but no difference between deep oscillation therapy and the standard of care. ${ }^{2}$ Similarly, Friesen ${ }^{4}$ found reductions in pain and swelling following the first treatment, but no significant reductions in days 2 to 5 following injury, similar to the standard of care. These findings indicate that deep oscillation therapy does not conclusively reduce the swelling and pain in athletes suffering from lateral ankle sprains after a single treatment or a 5-day protocol of deep oscillation therapy. ${ }^{2,4}$ Conversely, Aliyev ${ }^{3}$ used a 6-week conservative treatment protocol that demonstrated a significant reduction in pain and swelling, while also improving patient reported outcomes and patient satisfaction, making it possible that longer applications of deep oscillation therapy could be beneficial.

It should also be noted here that detailed information regarding the parameters used in the included studies were lacking. Reported frequencies ranged from 150 to $165 \mathrm{~Hz}$; however, the authors do not report if higher or lower frequencies produced a greater benefit, and 1 study omitted frequency altogether. ${ }^{3}$ Treatment duration in 2 studies 2,3 was set for 20 to 25 minutes but not reported in the third investigation. ${ }^{4}$ Unfortunately, this paucity of information lead to an overall low methodological quality (as measured by PEDro scores) and does not allow for the development of clinical recommendations into which parameters would be best for deep oscillation therapy. Adequate parameters for deep oscillation therapy, such as frequency, duration, and length of intervention, warrant further investigation.

Although the scope of this CAT was to assess the effectiveness of deep oscillation therapy on pain and swelling, the included 
Table 2 Characteristics of Included Studies

\begin{tabular}{|c|c|c|c|}
\hline \multirow[b]{2}{*}{ Study design } & Winkelmann et $\mathrm{al}^{2}$ & Aliyev $^{3}$ & Friesen $^{4}$ \\
\hline & \multicolumn{3}{|c|}{ Randomized control trial } \\
\hline Participants & $\begin{array}{l}38 \text { male and female college athletes } \\
\text { and recreationally active individuals } \\
(18-24 \text { y) } \\
\text { Subjects were randomized into experi- } \\
\text { mental or control groups } \\
\text { Subjects were eligible if they had suf- } \\
\text { fered a grade } 1 \text { or } 2 \text { lateral ankle sprain } \\
\text { by an athletic trainer within } 48 \mathrm{~h} \text { of } \\
\text { injury } \\
\text { Subjects were excluded if they were } \\
\text { currently taking any nonsteroidal anti- } \\
\text { inflammatory medication within the } \\
\text { past } 24 \text { h } \\
\text { Groups comparable at the start of the } \\
\text { study }\end{array}$ & $\begin{array}{l}43 \text { male }(70 \%) \text { and female amateur } \\
\text { athletes }(20-28 \text { y) } \\
\text { Subjects were randomized into treatment } \\
\text { or control groups } \\
\text { Subjects were eligible if they had suf- } \\
\text { fered from their first ankle sprain within } \\
\text { the last week and were willing to go } \\
\text { through a 6-wk treatment protocol } \\
\text { Subjects were excluded if they had a } \\
\text { bony injury of the ankle joint with sur- } \\
\text { gical treatment, concomitant injury } \\
\text { present, grade } 3 \text { sprain, and radiographic } \\
\text { degenerative disease of the ankle joint } \\
\text { Groups comparable at the start of the } \\
\text { study }\end{array}$ & $\begin{array}{l}21 \text { healthy, physically active, college } \\
\text { students with acute ankle sprains } \\
(18-25 \text { y) } \\
\text { Subjects were randomized into treatment } \\
\text { or control groups } \\
\text { Subjects were eligible if they had suf- } \\
\text { fered any inversion ankle injury within } \\
3 \text { d that resulted in swelling and point } \\
\text { tenderness } \\
\text { Subjects were excluded if they had any } \\
\text { of the following contraindications: acute } \\
\text { infection, active tuberculosis, infectious } \\
\text { skin disease, untreated thromboses, heart } \\
\text { complaints, and cardiac pacemakers. } \\
\text { Groups comparable at the start of the } \\
\text { study }\end{array}$ \\
\hline $\begin{array}{l}\text { Intervention } \\
\text { investigated }\end{array}$ & $\begin{array}{l}\text { Deep oscillation with Hivamat }{ }^{\circledR} 20 \text { min } \\
\text { (150-165 Hz and } 1: 1 \text { pulse to pause } \\
\text { time) } \\
20 \text { min of standard of care including ice, } \\
\text { compression wrap, and elevation at } 45^{\circ} \\
\text { of hip flexion } \\
\text { Control group received } 20 \text { min of deep } \\
\text { oscillation with placebo Hivamat }{ }^{\circledR} \text { prior } \\
\text { to start of care }\end{array}$ & $\begin{array}{l}\text { Both groups continuously wore an Air- } \\
\text { cast } \AA^{\circledR} \text { brace for } 6 \text { wk outside of treat- } \\
\text { ments. During treatments both groups } \\
\text { had ice with elevation and compression } \\
\text { Control group received } 20 \text { min of pla- } \\
\text { cebo deep oscillation, whereas treatment } \\
\text { group received } 20-25 \text { min of deep } \\
\text { oscillation (no other parameters } \\
\text { reported) }\end{array}$ & $\begin{array}{l}\text { Control group received } 20 \text { min of cold/ } \\
\text { intermittent compression via Game } \\
\text { Ready® at } 50-55^{\circ} \mathrm{C} \text { and } 20.32 \mathrm{~cm} \\
\text { Patients then received placebo deep } \\
\text { oscillation treatment for } 20 \text { min followed } \\
\text { by doing the following rehabilitation } \\
\text { exercise: } 2 \text { sets of writing the alphabet, } \\
15 \text { clockwise and } 15 \text { counterclockwise } \\
\text { circles, and } 4 \text {-way ankle range of motion } \\
\text { exercises at } 3 \text { sets of } 10 . \\
\text { Treatment group received above reha- } \\
\text { bilitation plan, but had deep oscillation } \\
\text { via Hivamat } \AA(150 \mathrm{~Hz})\end{array}$ \\
\hline $\begin{array}{l}\text { Outcome } \\
\text { measure(s) }\end{array}$ & $\begin{array}{l}\text { Primary outcome: impact of Hivamat }{ }^{\circledR} \\
\text { on pain and swelling } \\
\text { Secondary outcome: plantarflexion and } \\
\text { dorsiflexion range of motion }\end{array}$ & $\begin{array}{l}\text { Primary outcome: reduction of pain and } \\
\text { inflammation in patients } \\
\text { Secondary outcome: self-reported sta- } \\
\text { bility plantarflexion range of motion }\end{array}$ & $\begin{array}{l}\text { Primary outcome: effectiveness of deep } \\
\text { oscillation therapy to decrease swelling } \\
\text { following ankle sprains } \\
\text { Secondary outcome: effectiveness of } \\
\text { deep oscillation therapy to decrease pain } \\
\text { following ankle sprains }\end{array}$ \\
\hline Main findings & $\begin{array}{l}\text { Pain intensity significantly decreased } \\
\left(F_{1,35}=27.80 ; P<.001, \eta_{\mathrm{p}}^{2}=.44\right) ; \\
\text { however, no interaction term was found } \\
\text { Swelling had a significant decrease } \\
\left(F_{1,34}=12.35 ; P=.01, \eta_{\mathrm{p}}^{2}=.27\right) \text {, but no } \\
\text { interaction term was found } \\
\text { Significant increases were found for } \\
\text { plantarflexion range of motion } \\
\left(F_{1,35}=4.52 ; P=.04, \eta_{\mathrm{p}}^{2}=.01 \text { and dor- }\right. \\
\text { siflexion }\left(F_{1,35}=1.06 ; P=.31, \eta_{\mathrm{p}}^{2}=.03\right) \\
\text { within participants; yet, no interaction } \\
\text { term was found }\end{array}$ & $\begin{array}{l}\text { The subjective assessment of symptoms } \\
\text { (pain numeric rating scale) improved } \\
\text { significantly }(P<.001) \text { from } 9.1 \text { to } 2.1 \\
\text { points after treatment } \\
91 \% \text { of patients in the treatment group } \\
\text { were satisfied compared with } 72 \% \text { of } \\
\text { control group after } 6 \text { wk of treatment }\end{array}$ & $\begin{array}{l}\text { A significant difference between groups } \\
\text { was found on day } 1 \text { of the treatment for } \\
\text { pain reduction }\left(F_{1,24}=4.477, P=.045\right) \\
\text { No significant differences were found on } \\
\text { days } 2-5 \\
\text { A significant difference between groups } \\
\text { was found on day } 4 \text { of the treatment for } \\
\text { girth reduction }\left(F_{1,20}=4.951, P=.04\right)\end{array}$ \\
\hline Level of evidence & $1 b$ & $2 b$ & $2 b$ \\
\hline $\begin{array}{l}\text { Validity score } \\
\text { (if applicable) }\end{array}$ & PEDro $6 / 10$ & NA & PEDro $4 / 10$ \\
\hline Conclusion & $\begin{array}{l}\text { A single session of deep oscillation } \\
\text { therapy does not significantly improve } \\
\text { the benefits above and beyond that of the } \\
\text { standard care for acute lateral ankle } \\
\text { sprains }\end{array}$ & $\begin{array}{l}\text { The conservative treatment consisting of } \\
\text { Aircast }{ }^{\circledR} \text { brace and deep oscillation } \\
\text { show statistical significance in reducing } \\
\text { pain and inflammation }\end{array}$ & $\begin{array}{l}\text { The addition of deep oscillation therapy } \\
\text { to cryotherapy and compression is not } \\
\text { statistically significant in reducing pain } \\
\text { and swelling over a } 5 \text {-d period in acute } \\
\text { ankle sprains }\end{array}$ \\
\hline
\end{tabular}

articles did report other outcomes in these patients. One study included ankle range of motion in their assessment through goniometry and also assessed balance through the balance error scoring system. $^{2}$ This study found that patient plantarflexion and dorsiflexion ROM significantly improved equally for both groups over a 5-day span. Friesen ${ }^{4}$ also concluded that the average balance error scoring system score showed no improvement after deep oscillation therapy, indicating that deep oscillation therapy had no 
additive benefit to the standard of care. ${ }^{2,4}$ However, the readers should note that this was not the direct clinical question answered by this CAT; therefore, the effectiveness of deep oscillation therapy on other clinical outcomes needs to be investigated further.

Currently, there is no clinical link connecting deep oscillation therapy to the reduction of pain and inflammation in patients with lateral ankle sprains. The literature describes that using the standard of care (protection, rest, ice, compression, and elevation) has the same benefit as deep oscillation therapy in reducing pain and swelling. ${ }^{2,4}$ As deep oscillation therapy is a relatively new modality, more research is warranted to determine the effectiveness of deep oscillation therapy on pain and swelling, as well as other aspects of musculoskeletal injuries, such as patient-reported outcomes. In addition, further evaluation of deep oscillation therapy for other types of tissue injuries (ie, muscle, tendon, ligament) would add valuable information for its clinical utility in the future.

Clinicians incorporating deep oscillation therapy into lateral ankle injury rehabilitation programs should be aware of the lack of evidence supporting its use. Due to its lack of evidence in decreasing pain and swelling in ankle injuries, clinicians should consider an exercise-based approach using therapeutic exercise and muscle activation to increase lymphatic drainage and reduce swelling in the joint, coupled with cryotherapy for the reduction in pain. ${ }^{8,9}$ This CAT should be reviewed in 2 years to determine whether additional best evidence has emerged in the literature that may change the clinical bottom line for this clinical question.

\section{References}

1. Doherty C, Delahunt E, Caulfield B, Hertel J, Ryan J, Bleakley C. The incidence and prevalence of ankle sprain injury: a systematic review and meta-analysis of prospective epidemiological studies. Sports
Med. 2014;44(1):123-140. PubMed ID: 24105612 doi:10.1007/ s40279-013-0102-5

2. Winkelmann Z, Games K, Demchak T, Manley Z, Valencia C. Role of deep oscillation therapy in the treatment of acute lateral ankle sprains. Br J Sports Med. 2015;49(suppl 1):A1. doi:10.1136/bjsports2015-095573.2

3. Aliyev R. Better functional results of conservative treatment in fresh lateral ligament injuries of the ankle with additional deep oscillation. Phys Med Rehab Kuror. 2012;22(1):9-15. doi:10.1055/s-00311295494

4. Friesen L. Effect of deep oscillation therapy on the reduction of swelling and pain following acute ankle sprain [unpublished master's thesis]. Harrisonburg VA: James Madison University Harrisonburg; 2010.

5. OCEBM Levels of Evidence Working Group. The Oxford Levels of Evidence 2. Oxford Centre for Evidence-Based Medicine. https:// www.cebm.net/index.aspx?o $=5653$.

6. Kraft K, Kanter S, Janik H. Safety and effectiveness of vibration massage by deep oscillations: a prospective observational study. Evid Based Complement Alternat Med. 2013;2013(6):679248.

7. Jahr S, Schoppe B, Reisshauer A. Effect of treatment with low intensity and extremely low-frequency electrostatic fields (Deep Oscillation $\left.{ }^{\circledR}\right)$ on breast tissue and pain in patients with secondary breast lymphoedema. J Rehabil Med. 2008; 40(8):645-650. PubMed ID: 19020698 doi:10.2340/16501977-0225

8. Kerkhoffs GM, van den Bekerom M, Elders LAM, et al. Diagnosis, treatment and prevention of ankle sprains: an evidence-based clinical guideline. Br J Sports Med. 2012;46:854-860. doi:10.1136/bjsports2011-090490

9. van den Bekerom MPJ, Struijs PAA, Blankevoort L, Welling L, Niek van Dijk C, Kerkhoffs GMMJ (2012). What is the evidence for rest, ice, compression, and elevation therapy in the treatment of ankle sprains in adults? J Athl Train. 2012;47(4):435-443. doi:10.4085/ 1062-6050-47.4.14 